\title{
Anti-inflammatory role of Prunus persica L. Batsch methanol extract on lipopolysaccharide-stimulated glial cells
}

\author{
KYOUNG HEE SEO $^{1 *}$, SO YOUNG CHOI ${ }^{2 *}$, YEONSUN JIN $^{1}$, HEEBIN SON $^{1}$, YOUNG SUN KANG ${ }^{2}$, \\ SEUNG HYO JUNG ${ }^{3}$, YONG-IN KIM ${ }^{4}$, SANGMI EUM ${ }^{4}$, TRAN THE BACH ${ }^{5}$, HEE MIN YOO ${ }^{6}$, \\ WAN KYUNN WHANG ${ }^{7}$, SUN-YOUNG JUNG ${ }^{1}$, WONKU KANG ${ }^{1}$, HYUN MYUNG KO $^{8}$ and SUNG HOON LEE ${ }^{1}$ \\ ${ }^{1}$ College of Pharmacy, Chung-Ang University, Seoul 06974; ${ }^{2}$ Department of Biomedical Science and Technology, Konkuk \\ University, Seoul 05029; ${ }^{3}$ Department of Medicine, Research Institute of Medical Science, Konkuk University School of \\ Medicine, Chungju 27478; ${ }^{4}$ International Biological Material Research Center, Korea Research Institute of Bioscience \\ and Biotechnology, Daejeon 34141, Republic of Korea; ${ }^{5}$ Department of Botany, Institute of Ecology and Biological Resources, \\ Vietnam Academy of Science and Technology, Cau Giay, Hanoi 10000, Vietnam; ${ }^{6}$ Center for Bioanalysis, Korea Research \\ Institute of Standards and Science, Daejeon 34113; ${ }^{7}$ Pharmaceutical Botany Laboratory, College of Pharmacy, \\ Chung-Ang University, Seoul 06974; ${ }^{8}$ Department of Life Science, College of Science and \\ Technology, Woosuk University, Chungcheongbuk 27841, Republic of Korea
}

Received March 29, 2019; Accepted July 19, 2019

DOI: $10.3892 / \mathrm{mmr} .2020 .11016$

\begin{abstract}
Glial cells are the resident immune cells of the central nervous system. Reactive glial cells release inflammatory mediators that induce neurotoxicity or aggravate neurodegeneration. Regulation of glial activation is crucial for the initiation and progression of neuropathological conditions. Constituents of the peach tree (Prunus persica L. Batsch), which has a global distribution, have been found to exert therapeutic effects in pathological conditions, such as rashes, eczema and allergies. However, the therapeutic potential of its aerial parts (leaves, fruits and twigs) remains to be elucidated. The present study aimed to evaluate the anti-inflammatory role of $P$. persica methanol extract (PPB) on lipopolysaccharide
\end{abstract}

Correspondence to: Professor Sung Hoon Lee, College of Pharmacy, Chung-Ang University, 84 Heukseok, Dongjak, Seoul 06974, Republic of Korea

E-mail: sunghoonlee@cau.ac.kr

Professor Hyun Myung Ko, Department of Life Science, College of Science and Technology, Woosuk University, 66 Daehak, Jincheon, Chungcheongbuk 27841, Republic of Korea

E-mail:kohm@woosuk.ac.kr

${ }^{*}$ Contributed equally

Abbreviations: AD, Alzheimer's disease; IL-1 $\beta$, interleukin-1 $\beta$; LPS, lipopolysaccharide; MAPK, mitogen-activated protein kinase; NF- $\kappa \mathrm{B}$, nuclear factor $\kappa \mathrm{B}$; NO, nitric oxide; PPB, Prunus persica methanol extract; TNF- $\alpha$, tumor necrosis factor $\alpha$

Key words: anti-inflammatory effect, glial cells, MAPK pathway, $\mathrm{NF}-\kappa \mathrm{B}, \mathrm{NF}-\kappa \mathrm{B}$ pathway, proinflammatory mediators, Prunus persica $\mathrm{L}$. Batsch
(LPS)-stimulated glial cells. High-performance liquid chromatography coupled with tandem mass spectrometry analysis showed that PPB contained chlorogenic acid and catechin, which have antioxidant properties. Western blot and reverse transcription polymerase chain reaction results indicated that PPB reduced the transcription of various proinflammatory enzymes (nitric oxide synthase and cyclooxygenase-2) and cytokines [tumor necrosis factor- $\alpha$, interleukin (IL)-1 $\beta$ and IL-6] in LPS-stimulated BV2 cells. In addition, PPB inhibited the activation of $N F-\kappa B$ and various mitogen-activated protein kinases required for proinflammatory mediator transcription. Finally, nitrite measurement and immunocytochemistry results indicated that PPB also suppressed nitrite production and $\mathrm{NF}-\kappa \mathrm{B}$ translocation in LPS-stimulated primary astrocytes. Thus, PPB may be used as a potential therapeutic agent for neurodegenerative diseases and neurotoxicity via the suppression of glial cell activation.

\section{Introduction}

Glial cells are immune cells that reside in the central nervous system, and they have an important role in numerous neurodegenerative diseases, including Alzheimer's (AD), Parkinson's and Huntington's disease $(1,2)$. Glial cells are normally in a resting state; however, they are activated in response to an inflammatory stimulus. Despite comprising $<10 \%$ of the cells in the brain, the microglia regulate the neuroimmune system (3). Reactive microglia are observed in several neuroinflammatory conditions, including ischemia, brain injury and infection (4). These glial cells aggravate neurodegenerative diseases by secreting inflammatory mediators or proinflammatory cytokines that induce neurotoxicity (5-7). In addition, they release soluble toxins, which induce reactive A1 astrocytes that are neurotoxic (8). Similarly, astrocytes, which are the most abundant brain cell types, cause several 
brain inflammatory conditions by secreting proinflammatory mediators in response to a neuroinflammatory stimulus $(9,10)$. Elevated nitric oxide (NO) levels have been observed in glial cells of patients with AD or ischemia $(11,12)$. In addition, reactive glial cells promote the production of tumor necrosis factor (TNF) $\alpha$, interleukin (IL) $1 \beta$, and IL-6, which contribute to the development of neuroinflammatory conditions and brain damage (13-15). Therefore, reactive glial cell regulation is crucial for the initiation and progression of neurodegenerative diseases and neuronal cell death $(4,16,17)$.

Plant-based anti-inflammatory compounds may be potential sources of safe and effective drugs $(18,19)$. Traditional herbal medicines derived from natural products and their active constituents have been extensively studied, and several ingredients from natural products have been found to be beneficial for the treatment of neuroinflammatory and neurodegenerative diseases, given their ability to suppress glial activation (20-22). Panax ginseng (23), Curcuma longa (24), and Camellia sinensis (25) display neuroprotective effects by suppressing neuroinflammatory cytokine secretion via glial cell activation. In addition, natural products are safe, inexpensive and easy to obtain. Therefore, the discovery of a novel natural product that can regulate glial activation is crucial for the development of neurodegenerative disease treatments (26).

The peach tree (Prunus persica L. Batsch) was initially reported as a deciduous tree native to the northwest region of China. It is now grown worldwide, including the temperate regions of eastern Asia, including Vietnam, China, Japan and Korea (27). Various parts of $P$. persica have therapeutic effects. The dried seeds of ripened $P$. persica fruit are widely used in traditional medicine (Persicae Semen) in Korea and China, and persicaside, an alkaloid compound derived from $P$. persica seeds, inhibits the production of NO (28). $P$. persica flowers are used for the treatment of rashes and eczema (29). The flavonoid compounds 4-O-caffeoylquinic acid, quercetin-3-O-rhamnoside and kaempferol glycoside, which are $P$. persica flower derivatives, have anti-inflammatory properties (30). In addition, $P$. persica fruit has anti-allergenic properties (31). P. persica roots can suppress the growth of liver cancer cells (27), and its leaves have antioxidant and antibacterial properties (32-34). However, the antioxidant properties of $P$. persica leaves have only been evaluated with in vitro analysis (e.g., 2,2-diphenyl-1-picrylhydrazyl assay) $(32,33)$. Therefore, in vivo biological evidence is required.

The present study aimed to investigate the anti-inflammatory effects of $P$. persica aerial parts (leaves, fruits and twigs) on glial cells. P. persica methanol extract (PPB) was applied to BV2 cells and primary astrocytes. PPB inhibited the production of proinflammatory mediators and cytokines in lipopolysaccharide (LPS)-stimulated BV2 cells by suppressing $N F-\kappa B$ translocation and mitogen-activated protein kinase (MAPK) signaling pathways. Furthermore, PPB also inhibited $\mathrm{NO}$ production and NF- $\kappa \mathrm{B}$ translocation in cultured primary astrocytes.

\section{Materials and methods}

Materials. DMEM and FBS were purchased from Gibco (Thermo Fisher Scientific, Inc.). Chlorogenic acid, catechin, quercetin, quercetin-3-O-glucoside, formic acid, diclofenac, and LPS (Escherichia coli O55:B5) were purchased from Sigma-Aldrich (Merck KGaA). Antibodies against inducible nitric oxide synthase (iNOS; cat. no. 610431; BD Biosciences), cyclooxygenase-2 (COX-2; 1:2,000; cat. no. sc-376861; Santa Cruz Biotechnology, Inc.), ERK [1:2,000; cat. no. 9102S; Cell Signaling Technology, Inc. (CST)], phosphorylated (p)-ERK (1:1,000; cat. no. 9101S; CST), JNK (1:2,000; cat. no. 9258S; CST), p-JNK (1:1,000; cat. no. 9251S; CST), p38 (1:2,000; cat. no. 9212S; CST), p-p38 (1:1,000; cat. no. 9211S; CST), inhibitor

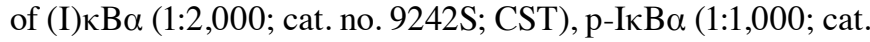
no. 2859S; CST), and $\beta$-actin (1:5,000; cat. no. sc-47778; Santa Cruz Biotechnology, Inc.) were used for western blot analysis. Horseradish peroxidase (HRP)-conjugated secondary antibodies for western blots, goat anti-mouse $\operatorname{IgG}$ (1:5,000; cat. no. 1706516; Bio-Rad Laboratories, Inc.) and goat anti-rabbit IgG (1:5,000; cat.no. 1706515; Bio-Rad Laboratories, Inc.) were used. For immunocytochemistry, p65 (1:500; cat. no. 8242S; CST Biological Reagents Co., Ltd.) and glial fibrillary acidic protein (GFAP; 1:500; cat. no. MAB3402; Merck KGaA) were used as primary antibodies, and Alexa Fluor 488 donkey anti-mouse IgG (1:500; cat. no. ab150105; Abcam) and Alexa Fluor 594 donkey anti-rabbit IgG (1:500; cat. no. ab150076; Abcam) were used as secondary antibodies.

Preparation of PPB. In 2008, P. persica was obtained from various regions in Vietnam (Bằng Lũng, Chợ Đồn, and Bắc Kạn). The samples were authenticated by the chief executive of the Institute of Ecology and Biological Resources. It is characterized by 4-7 $\mathrm{m}$ tall, dark green, deciduous leaves and flowers in single, semi-double and double form in colors from white to deep red. A voucher specimen (KRIB0018669, accession number of KRIBB) was deposited in the herbarium of the Korea Research Institute of Bioscience and Biotechnology. $P$. persica dried and refined aerial parts (leaves, fruits and twigs; total weight, $63 \mathrm{~g}$ ) were extracted with $600 \mathrm{ml}$ of $99.9 \%$ (v/v) methanol and were repeatedly sonicated with $1,500 \mathrm{~W}$ input and $40 \mathrm{kHz}$ frequency for $15 \mathrm{~min}$ at 2-h intervals for 3 days. All procedures were performed at $45^{\circ} \mathrm{C}$. The product was filtered through non-fluorescent cotton and concentrated by rotary evaporation using an N-1000SWD device (EYELA Co., Ltd.) under reduced pressure at $45^{\circ} \mathrm{C}$. Finally, $8.05 \mathrm{~g}$ of PPB was obtained by freeze-drying and then dissolved in DMSO (Sigma-Aldrich; Merck KGaA).

Contents of the marker substances in PPB. Chlorogenic acid, catechin, quercetin and quercetin-3-O-glucoside were selected as marker substances in PPB based on a previous study (35). The extract contents were measured using high-performance liquid chromatography coupled with tandem mass spectrometry (HPLC-MS/MS). Briefly, to identify the product ions of each substance, the marker substances $(100 \mathrm{ng} / \mathrm{ml})$ were individually infused into the mass spectrometer at a flow rate of $10 \mu \mathrm{l} / \mathrm{min}$. Precursor ions and fragmentation patterns were monitored in a negative-ion mode. Using an API 4000 LC/MS/MS system (AB SCIEX Analytical Instrument Trading Co.) equipped with an electrospray ionization interface, major peaks in the MS/MS scan were used to quantify the substances. The compounds were separated on a reversed-phase column $\left(\mathrm{Kinetex}^{\circledR} \mathrm{C} 18,2.6-\mu \mathrm{m}\right.$ particle size, 100x2.1 mm internal diameter; Phenomenex Ltd.) in the 
mobile phase of a water:acetonitrile mixture at a 3:7 (v/v) ratio including $0.1 \%$ formic acid. The column was heated at $30^{\circ} \mathrm{C}$, and the mobile phase was delivered at a flow rate of $0.2 \mathrm{ml} / \mathrm{min}$ using an HP 1100 series pump (Agilent Technologies, Inc.). The injection volume was $5 \mu \mathrm{l}$. The turbo ion spray interface was operated at $-4,200 \mathrm{~V}$ at $450^{\circ} \mathrm{C}$. Nitrogen was used as a curtain gas at 35 psi, and air dried was nebulized as a collision gas at 4 psi and ion source gases 1 (45 psi) and 2 (55 psi). The ion transitions of the precursor to the product ion were monitored in negative mode as deprotonated ions $[\mathrm{M}-\mathrm{H}]^{-}$at $\mathrm{m} / \mathrm{z} 353.0$ $\rightarrow 190.8$ [declustering potential (DP), $-60 \mathrm{eV}$; collision energy (CE), -22 eV] for chlorogenic acid, $289.0 \rightarrow 244.8(\mathrm{DP},-90 \mathrm{eV}$; $\mathrm{CE},-20 \mathrm{eV}$ ) for catechin, $301.0 \rightarrow 151.0(\mathrm{DP},-100 \mathrm{eV}, \mathrm{CE}$, $-32 \mathrm{eV}$ ) for quercetin, $463.1 \rightarrow 300.0(\mathrm{DP},-120 \mathrm{eV}, \mathrm{CE},-36 \mathrm{eV})$ for quercetin-3-O-glucoside, and $296.1 \rightarrow 251.7(\mathrm{DP},-100 \mathrm{eV}$, $\mathrm{CE},-32 \mathrm{eV}$ ) for diclofenac (internal standard). Quantification was performed by selective reaction monitoring of deprotonated precursor ions and related product ions using the ratio of the area under the peak for each solution. All analytical data were processed using Analyst software (version 1.5.2; Applied Biosystems; Thermo Fisher Scientific, Inc.). Standard marker substance solutions were serially diluted with methanol including the internal standard (IS, $100 \mathrm{ng} / \mathrm{ml}$ ) to obtain $10-1,000 \mathrm{ng} / \mathrm{ml}$ concentrations. Using linear regression, two calibration graphs were derived from the ratios between the areas under the peaks for each substance and those of the IS. PPB (20 mg/vial) was dissolved in $1 \mathrm{ml}$ of methanol and was serially diluted with methanol including the IS by 1,000 -fold. The concentrations of each marker substance were predicted using the calibration graph, and their contents within the extracts were calculated.

Cell culture and treatment. The BV2 cells (CLC catalog code, ATL03001) were provided by Dr Dong-Kug Choi (Konkuk University, Chungju-si, Chungcheongbuk-do, Republic of Korea) and were maintained in DMEM containing 5\% FBS, $100 \mathrm{U} / \mathrm{ml}$ penicillin, and $100 \mu \mathrm{g} / \mathrm{ml}$ streptomycin (Welgene, Inc.) in a humidified incubator with air containing $5 \% \mathrm{CO}_{2}$. In all of the experiments, 500,000 cells were plated and treated with PPB $(20,100$ and $200 \mu \mathrm{g} / \mathrm{ml})$ for $1 \mathrm{~h}$ prior to LPS treatment (200 ng/ml, cat. no. L2880; Sigma-Aldrich; Merck KGaA), and the vehicle was a DMSO only treatment $(0.1 \%)$. BV2 cells were treated with LPS for 6 and $24 \mathrm{~h}$ for reverse transcriptase polymerase chain reaction (RT-PCR) and western blots, respectively.

Hydrogen peroxide $\left(\mathrm{H}_{2} \mathrm{O}_{2}, 250 \mu \mathrm{M}\right)$ was applied to BV2 cells for $24 \mathrm{~h}$ to measure cytotoxicity.

Primary astrocytes were prepared from the cortices of postnatal day 2 Sprague-Dawley rats (7-9 g), as previously described by McCarthy and de Villis (36). Postnatal day 1 Sprague-Dawley rats were purchased (Young Bio) and were maintained for $24 \mathrm{~h}$ in controlled temperature $\left(20-25^{\circ} \mathrm{C}\right)$, humidity (50-55\%) and 12-h light/dark cycle with their mother. A total of 6 animals ( 3 males and 3 females) were used for this study. All animals were handled in accordance with the Principle of Laboratory Animal Care (37) and the study was approved by the Institutional Animal Care and Use Committee of Chung-Ang University (2017-00093).

Briefly, the astrocytes were plated in poly-d-lysine (PDL)-coated T-75- $\mathrm{cm}^{2}$ flasks in DMEM/F12 (Gibco;
Thermo Fisher Scientific, Inc.) supplemented with 10\% FBS, $100 \mathrm{U} / \mathrm{ml}$ penicillin, and $100 \mu \mathrm{g} / \mathrm{ml}$ streptomycin. Microglia were removed at 7 days in vitro (DIV), and subcultured astrocytes at 15 DIV were used for further experiments. Primary astrocytes were treated with PPB $(20,100$ and $200 \mu \mathrm{g} / \mathrm{ml})$ for $1 \mathrm{~h}$ prior to LPS treatment $(10 \mathrm{ng} / \mathrm{ml})$, and the control group was treated with vehicle (DMSO; $0.1 \%$ ).

Cell viability. Cell viability was determined using the MTT assay. Cells were treated with PPB for $24 \mathrm{~h}$ and incubated with MTT (100 $\mu \mathrm{g} / \mathrm{ml})$ for $2 \mathrm{~h}$. DMSO was added to dissolve the insoluble formazan crystals that had formed within viable cells, and the absorbance was measured at $540 \mathrm{~nm}$.

Propidium iodide (PI) staining. BV2 cells, which were protected from the light, were fixed with $70 \%$ ethanol at for $30 \mathrm{~min}$ at $20-25^{\circ} \mathrm{C}$ and stained using FxCycle PI/RNase staining solution (cat. no. F10797; Thermo Fisher, Inc.) for $30 \mathrm{~min}$ at $20-25^{\circ} \mathrm{C}$. Nuclei were stained with DAPI (cat. no. D1306; Invitrogen; Thermo Fisher Scientific, Inc.) for $10 \mathrm{~min}$ at $20-25^{\circ} \mathrm{C}$. Cell images were visualized using a confocal microscope (Zeiss $\mathrm{GmbH})$.

Nitrite measurement. NO release was measured from nitrite levels using a Griess reagent $(0.1 \%$ naphthylethylenediamine and $1 \%$ sulfanilamide in $\left.5 \% \mathrm{H}_{3} \mathrm{PO}_{4}\right)$. The supernatant was mixed with an equal volume of Griess reagent for $5 \mathrm{~min}$ at $20-25^{\circ} \mathrm{C}$. Mixture absorbance was measured at $540 \mathrm{~nm}$ using a microplate reader (Tecan Group, Ltd.).

Isolation of total RNA and RT-PCR. Total RNA was isolated from LPS-stimulated cells using TRIzol reagent (Invitrogen; Thermo Fisher Scientific, Inc.) according to the manufacturer's instructions. Reverse transcription was conducted for $5 \mathrm{~min}$ at $70^{\circ} \mathrm{C}$ and $5 \mathrm{~min}$ at $4^{\circ} \mathrm{C}$ with total RNA $(1 \mu \mathrm{g})$ and GoScript Reverse Transcriptase (Promega Corporation). cDNA was subsequently amplified by RT-PCR with specific primers and GoTaq DNA polymerase (Promega Corporation). The PCR primer sets were as follows: iNOS (sense, 5'-GAGGTACTCAGCGTGCTCCA-3'; antisense, 5'-AGGGAGGAAAGGGAGAGAGG-3'), COX-2 (sense, 5'-TGAGTGGTAGCCAGCAAAGC-3'; antisense, 5'-CTG CAGTCCAGGTTCAATGG-3'), TNF- $\alpha$ (sense, 5'-AGG GAGAGTGGTCAGGTTGC-3'; antisense, 5'-CAGCCTGGT CACCAAATCAG-3'), IL-1 $\beta$ (sense, 5'-CAAGGAGAACCA AGCAACGA-3'; antisense, 5'-TTGGCCGAGGACTAA GGAGT-3'), IL-6 (sense, 5'-GGAGGCTTAATTACACAT GTT-3'; antisense, 5'-TGATTTCAAGATGAATTGGAT-3'), and GAPDH (sense, 5'-CCAGTAGACTCCACTCACG-3'; antisense, 5'-CCTTCCACAATGCCAAAGTT-3'). Thermal cycling was performed as follows: Initial denaturation $\left(95^{\circ} \mathrm{C}\right.$ for $2 \mathrm{~min})$, amplification $\left(95^{\circ} \mathrm{C}\right.$ for $1 \mathrm{~min} ; 55^{\circ} \mathrm{C}$ for $1 \mathrm{~min}$ and $72^{\circ} \mathrm{C}$ for $1 \mathrm{~min}, 35$ cycles $)$, and final extension $\left(72^{\circ} \mathrm{C}\right.$ for $5 \mathrm{~min}$ ). After amplification, the PCR products were resolved by agarose gel electrophoresis on $1 \%$ agarose gel containing 1X TAE (Biosesang, Inc.) and 1X Midori green advance (Nippon Genetics Europe $\mathrm{GmbH}$ ), and visualized using a LAS-3000 device (FujiFilm). The band intensity was determined using ImageJ software (version 1.38; National Institutes of Health). 


\section{Quercetin}
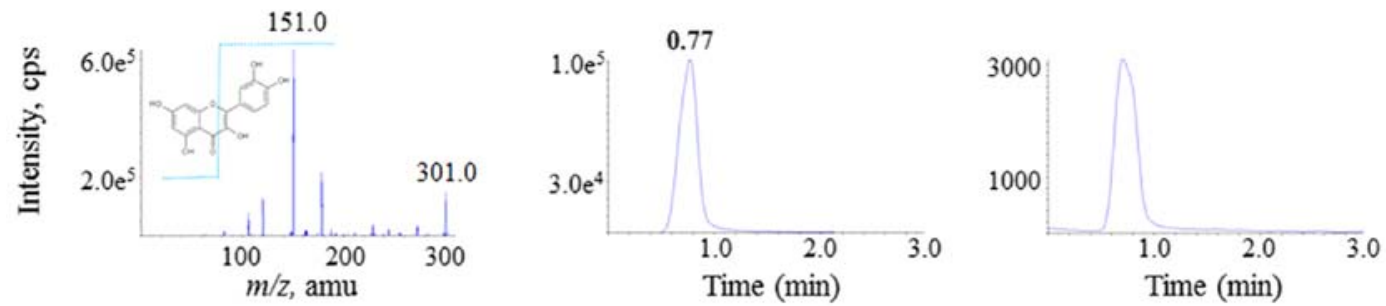

Quercetin-3- $O$-glucoside
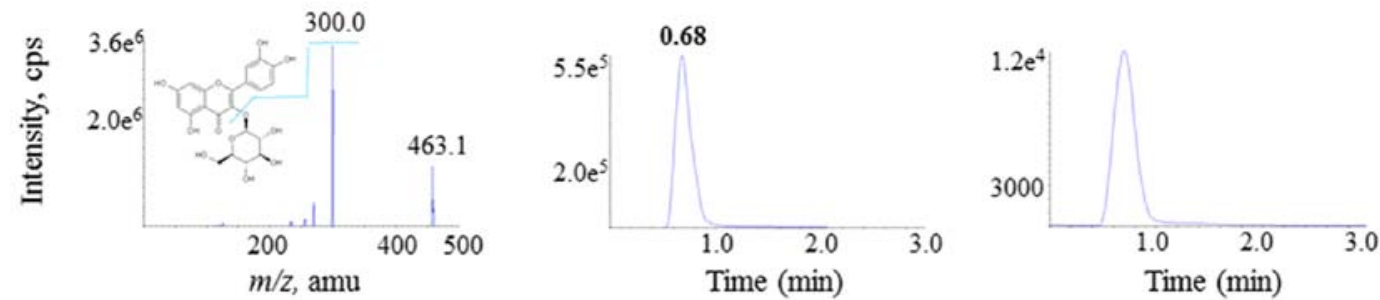

Catechin
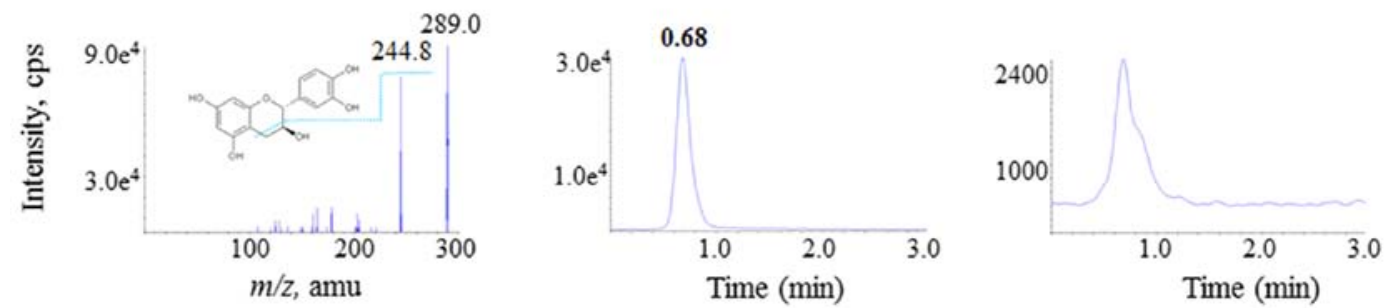

Chlorogenic acid
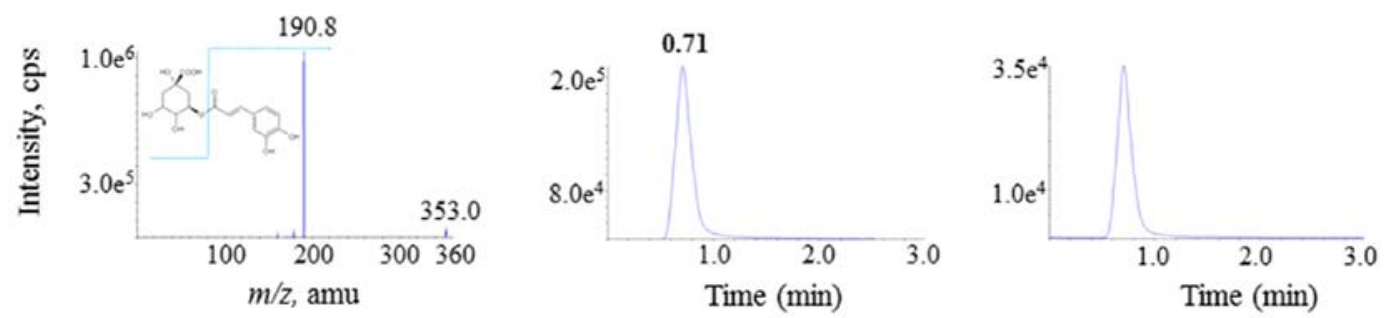

Figure 1. Contents of substances in PPB. Mass spectra and proposed fragment ions (left), chromatograms of the $250 \mathrm{ng} / \mathrm{ml}$ standard solution (middle), and PPB solution diluted 1,000-fold (right). PPB, Prunus persica methanol extract; cps, counts per second.

Western blot analysis. Lysates were extracted from cells using RIPA buffer (Biosesang, Inc.) and total protein was determined by BCA assay. A total amount of $30 \mu \mathrm{g}$ of proteins were loaded. Proteins were separated using 10\% SDS-PAGE and transferred to nitrocellulose membranes (Whatman; GE Healthcare Life Sciences). The membranes were blocked with $5 \%$ skimmed milk (Biosesang, Inc.) in TBS-Tween $(0.1 \%$ Tween-20) for $1 \mathrm{~h}$ at $20-25^{\circ} \mathrm{C}$. The membranes were incubated with primary antibodies for overnight at $4^{\circ} \mathrm{C}$. Then, the membranes were incubated with HRP-conjugated secondary antibodies for $1 \mathrm{~h}$ at $20-25^{\circ} \mathrm{C}$. The bands were developed using enhanced chemiluminescence solution (WEST-ZOL Plus, iNtRON Biotechnology) and visualized with the LAS-3000 device (FujiFilm). The band intensity was analyzed with ImageJ software (version 1.38; National Institutes of Health).

Immunocytochemistry. Cells were fixed with $4 \%$ paraformaldehyde for $15 \mathrm{~min}$ at $20-25^{\circ} \mathrm{C}$ and then permeabilized with $0.1 \%$ Triton $\mathrm{X}-100$ for $10 \mathrm{~min}$. Coverslips were incubated with blocking buffer (1\% BSA in PBS) for $1 \mathrm{~h}$ at $20-25^{\circ} \mathrm{C}$ and then incubated with primary antibodies for overnight at $4^{\circ} \mathrm{C}$. Coverslips were incubated with secondary antibodies for $1 \mathrm{~h}$ at $20-25^{\circ} \mathrm{C}$, and images were visualized using a confocal microscopy (400x magnification; Carl Zeiss).

Statistical analysis. Data were expressed as mean \pm SEM from $\geq 3$ independent experiments. Statistical analyses were performed using GraphPad Prism 5.0 software (version 5.01; GraphPad Software, Inc.). The significance of each group was determined using one-way ANOVA followed by Turkey's post-hoc test. $\mathrm{P}<0.05$ was considered to indicate a statistically significant difference.

\section{Results}

Contents of the marker substances in PPB. Fig. 1 illustrates the mass spectra and proposed fragment ions of the four marker substances (left column), chromatograms of the standard 

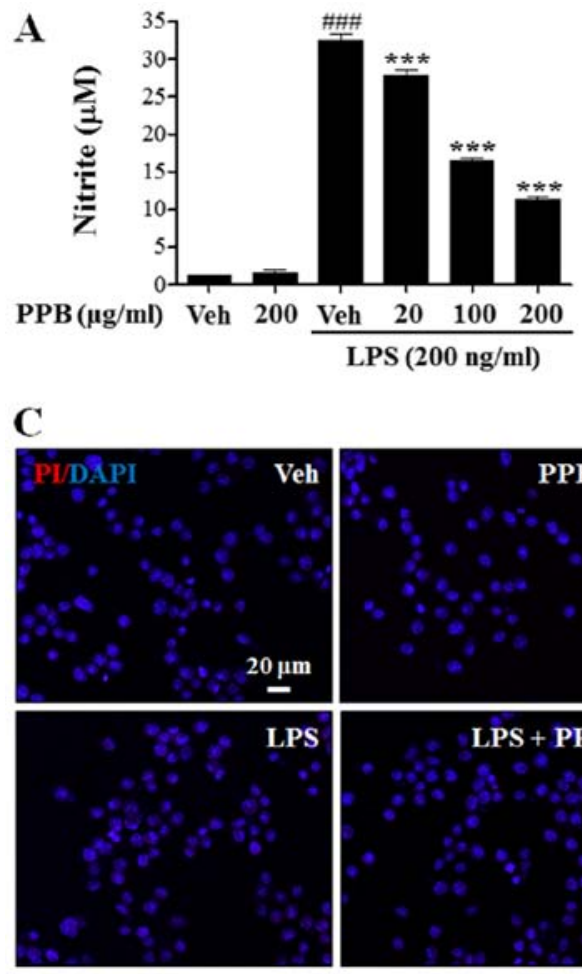
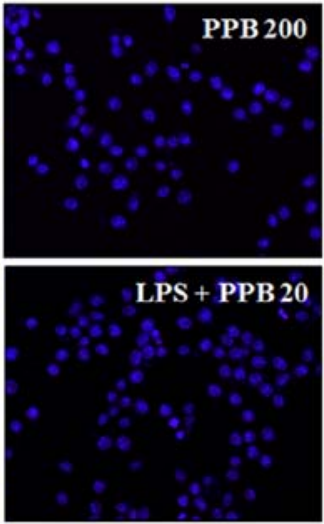
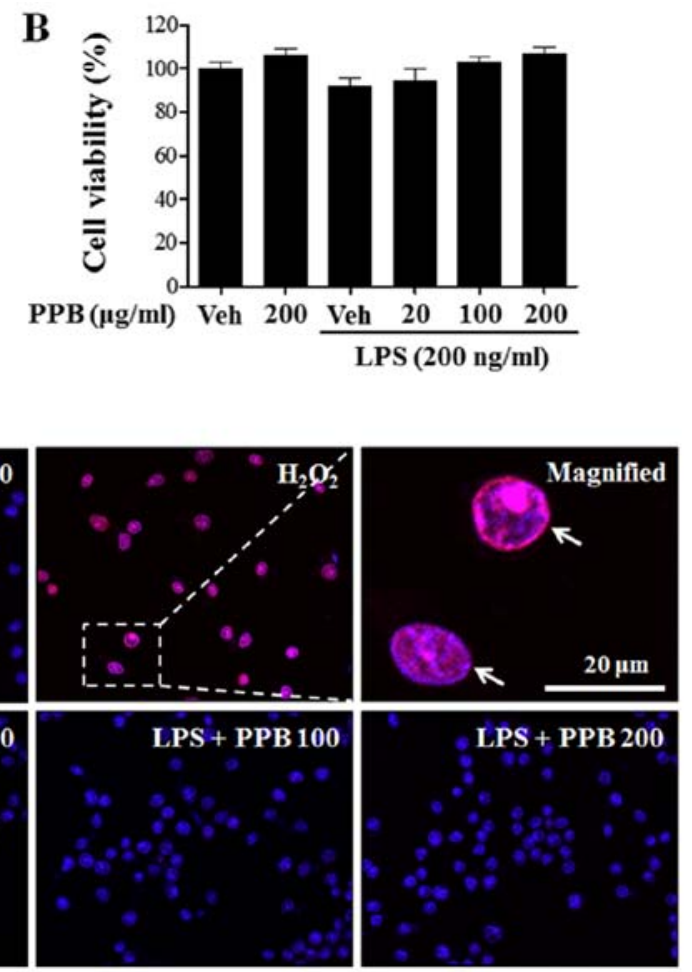

Figure 2. PPB suppressed nitric oxide release in LPS-stimulated BV2 cells. (A) Nitrite was measured in LPS-stimulated BV2 cells. (B) Cell viability was measured with the MTT assay. (C) Cell cytotoxicity was measured with PI staining. $\mathrm{H}_{2} \mathrm{O}_{2}$ induces cytotoxicity, and PI-positive cells are magnified (arrow).

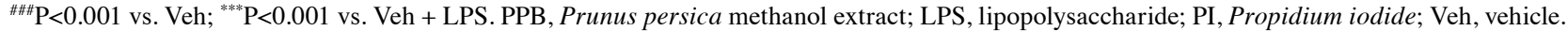

solution $(250 \mathrm{ng} / \mathrm{ml})$ of each substance (middle column), and PPB solution that was diluted 1,000-fold (right column). PPB contained $0.193 \%$ chlorogenic acid, $0.097 \%$ catechin, $0.040 \%$ quercetin and $0.035 \%$ quercetin-3-O-glucoside.

Effect of PPB on NO release in LPS-stimulated BV2 cells. To examine the anti-inflammatory role of $\mathrm{PPB}$, the nitrite levels in LPS-stimulated BV2 cells was measured. LPS-induced upregulation of NO production was reduced by PPB treatment in a dose-dependent manner (Fig. 2A). The MTT assay showed that PPB did not have a significant effect on cell viability (Fig. 2B). To further examine the presence of cytotoxicity, PI staining was performed as previously described (38) and quantitatively showed that $\mathrm{H}_{2} \mathrm{O}_{2}$, but not $\mathrm{PPB}$, induced cellular toxicity (Fig. 2C). These results suggested that PPB suppressed NO release in LPS-stimulated BV2 cells without inducing cellular toxicity.

Effect of PPB on iNOS, COX-2 and proinflammatory cytokine expression. LPS promoted iNOS and COX-2 protein expression, which was inhibited by PPB (Fig. 3A). PPB attenuated LPS-induced elevation of iNOS and COX-2 mRNA (Fig. 3B). Therefore, PPB inhibits iNOS and COX-2 expression in LPS-stimulated BV2 cells. To further investigate the anti-inflammatory role of PPB, TNF- $\alpha$, IL-1 $\beta$ and IL-6 mRNA expression levels were investigated. PPB alleviated LPS-induced enhancement of proinflammatory cytokines (Fig. 3C). Notably, PPB significantly inhibited iNOS and COX-2 expression at a lower concentration $(100 \mu \mathrm{g} / \mathrm{ml})$ than the concentration that affected TNF- $\alpha$, IL-1 $\beta$, and IL- 6 expression $(200 \mu \mathrm{g} / \mathrm{ml})$. The present results may indicate that PPB had preferential inhibitory effects on iNOS and COX-2 compared with TNF- $\alpha$, IL-1 $\beta$ and IL-6 in LPS-stimulated BV2 cells.

Effect of PPB on LPS-induced NF- $\kappa$ B pathways. NF- $\kappa \mathrm{B}$ is a major transcription factor that regulates the expression of proinflammatory cytokines during inflammation. In response

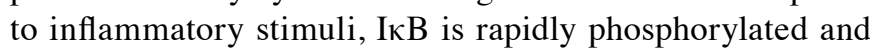
degraded, and subsequently dissociates from $\mathrm{NF}-\kappa \mathrm{B}$, which translocates to the nucleus, leading to the transcription of proinflammatory mediators and cytokines $(39,40)$. To clarify the underlying mechanism of the anti-inflammatory effects of PPB, the NF- $\mathrm{BB}$ signaling pathway was investigated. Normally, the level of I $\mathrm{B} \alpha$ expression is high, whereas that of $\mathrm{p}-\mathrm{I} \kappa \mathrm{B} \alpha$ expression is low. In the present study, LPS exposure decreased $\mathrm{I} \kappa \mathrm{B} \alpha$ expression and enhanced $\mathrm{p}-\mathrm{I} \kappa \mathrm{B} \alpha$ expression (Fig. 4A). PPB ameliorated the LPS-induced alteration of I $\mathrm{B} \alpha$ and $\mathrm{p}-\mathrm{I} \kappa \mathrm{B} \alpha$ expression. To further examine the effect of PPB on $\mathrm{p} 65$ translocation, the expression of $\mathrm{p} 65$ was investigated by immunostaining. As expected, PPB suppressed LPS-induced p65 translocation into the nucleus (Fig. 4B). The present results indicated that $\mathrm{PPB}$ regulates proinflammatory cytokine expression by suppressing the NF- $\kappa \mathrm{B}$ signaling pathway.

Effect of PPB on LPS-induced MAPK activation. In microglia, LPS exposure enhances iNOS and TNF- $\alpha$ expression, which is accompanied by the activation of MAPK signaling pathways, including the ERK, JNK and p38 pathways (16). In addition, MAPK is involved in COX-2 and iNOS production in LPS-stimulated microglial cells (41). To further examine the underlying mechanism of PPB, MAPK activation was investigated. PPB repressed LPS-induced phosphorylation of ERK, 
A

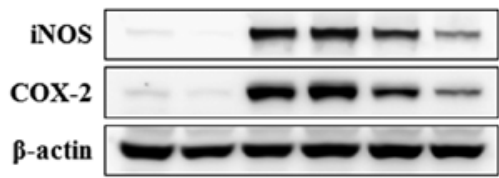

PPB $(\mu \mathrm{g} / \mathrm{ml}) \quad$ Veh 200 Veh $20 \quad 100 \quad 200$

LPS (200 ng/ml)

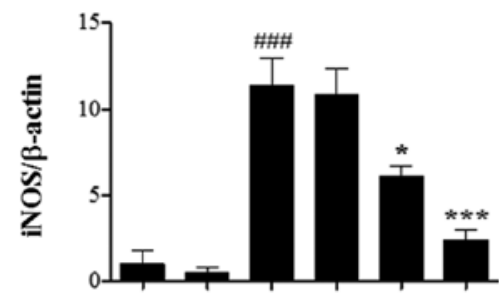

PPB $(\mu \mathrm{g} / \mathrm{ml}) \quad$ Veh $200 \quad$ Veh $\quad 20 \quad 100 \quad 200$ LPS (200 ng/ml)

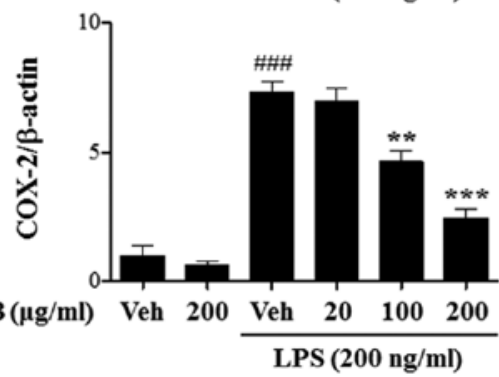

C
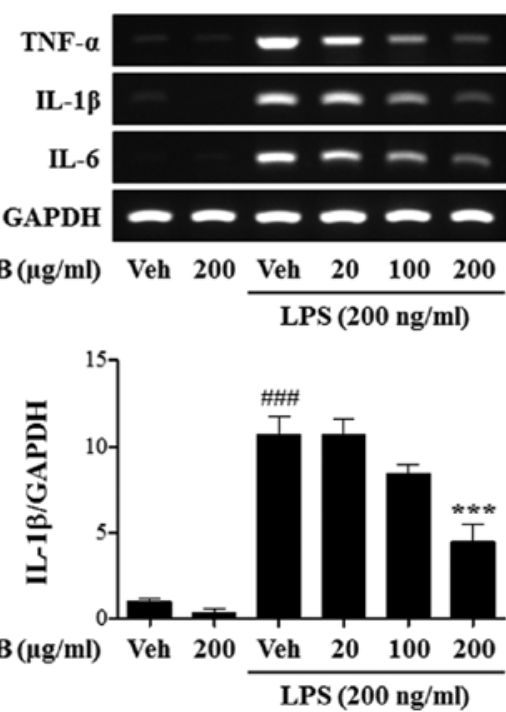

B

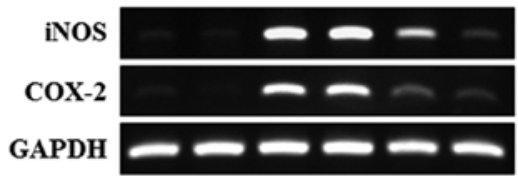

PPB $(\mu \mathrm{g} / \mathrm{ml})$ Veh 200 Veh $20 \quad 100 \quad 200$

LPS (200 ng/ml)

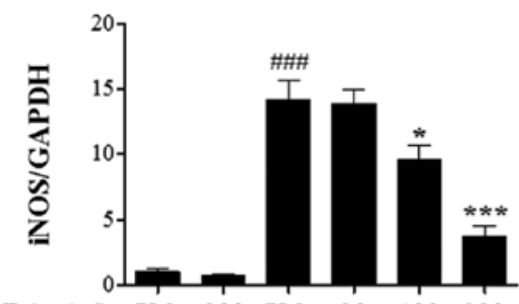

PPB $(\mu \mathrm{g} / \mathrm{ml}) \quad$ Veh $200 \quad$ Veh $20 \quad 100 \quad 200$

LPS (200 ng/ml)
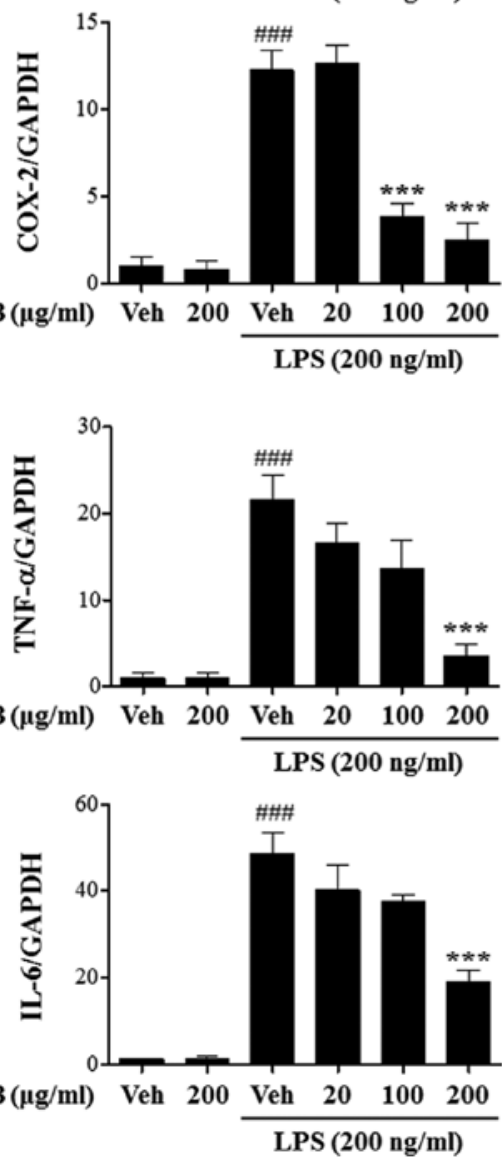

Figure 3. PPB inhibits proinflammatory mediator expression in LPS-stimulated BV2 cells. (A) iNOS and COX-2 protein expression is normalized with $\beta$-actin (B) mRNA expression levels of iNOS and COX-2. iNOS and COX-2 mRNA expression was normalized with GAPDH. (C) TNF- $\alpha$, IL-1 $\beta$ and IL-6 protein expression was normalized with GAPDH. ${ }^{\# \# /} \mathrm{P}<0.001$ vs. Veh; ${ }^{\mathrm{P}}<0.05,{ }^{* *} \mathrm{P}<0.01$, and ${ }^{* * * *} \mathrm{P}<0.001$ vs. Veh $+\mathrm{LPS}$. PPB, Prunus persica methanol extract; LPS, lipopolysaccharide; iNOS, inducible nitric oxide synthase; COX-2, cyclooxygenase-2; TNF, tumor necrosis factor; IL, interleukin; Veh, vehicle.

JN and p38 (Fig. 5). Notably, PPB significantly suppressed the JNK phosphorylation at a lower concentration $(20 \mu \mathrm{g} / \mathrm{ml})$ than that for ERK or p38 $(100 \mu \mathrm{g} / \mathrm{ml})$. The present results indicated that PPB preferentially inhibited JNK in LPS-stimulated BV2 cells. Taken together, the present results demonstrated that PPB exerts an anti-inflammatory effect in LPS-stimulated BV2 cells through the inhibition of NF- $\mathrm{B}$ and MAPK pathway activation.

Effect of $P P B$ on $N O$ release and p65 translocation in LPS-stimulated primary astrocytes. To further evaluate the suppressive effect of PPB on neuroinflammation, NO production in primary cultured astrocytes was investigated. Consistent with the BV2 cell results, PPB also suppressed LPS-induced NO production without inducing cellular toxicity (Fig. 6A and B). In addition, immunostaining results indicated that PPB successfully alleviated LPS-induced p65 translocation into the nucleus (Fig. 6C). The present results indicated the anti-inflammatory role of PPB in glial cell activation by repressing repressed NO production and p65 translocation in primary astrocytes (Fig. S1). 

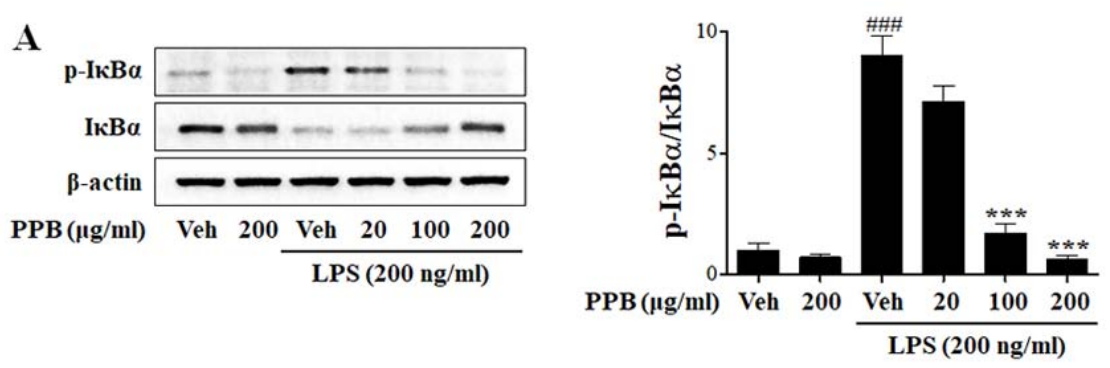

B
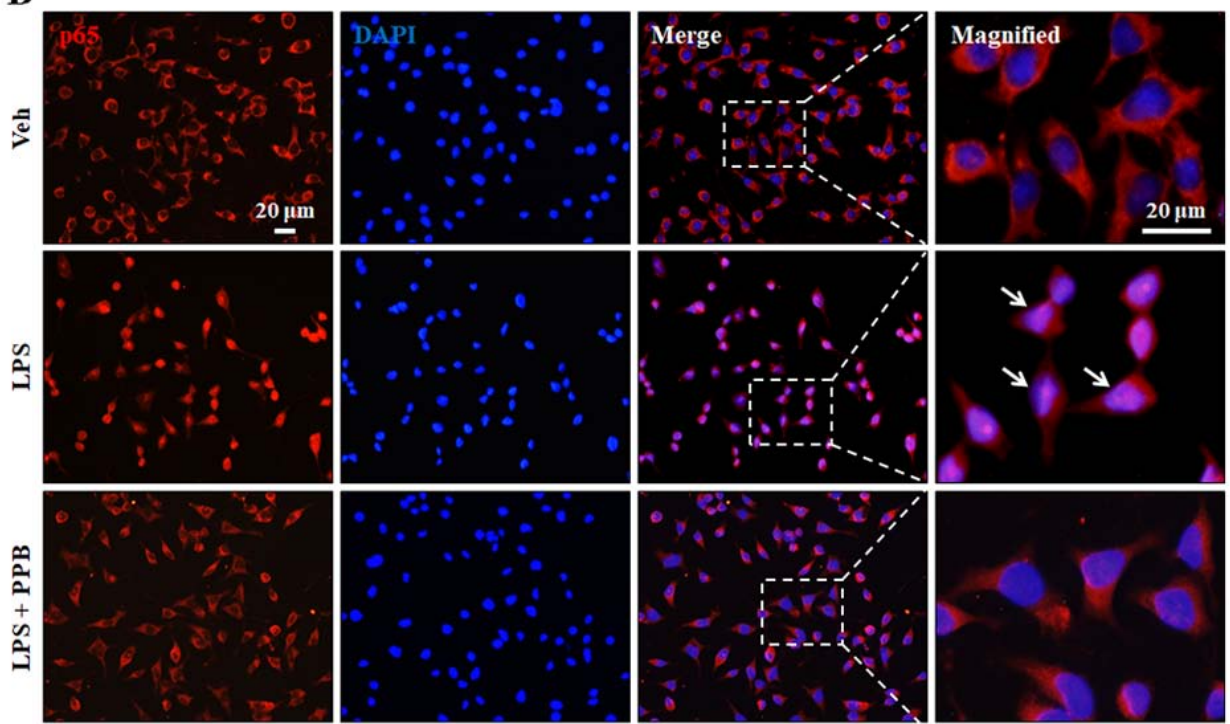

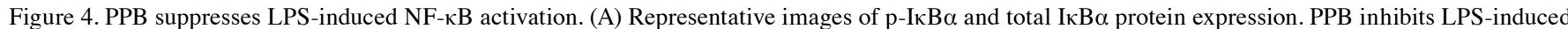
$\mathrm{p}-\mathrm{I} \kappa \mathrm{B} \alpha$ enhancement. $\mathrm{p}-\mathrm{I} \kappa \mathrm{B} \alpha$ is normalized with $\mathrm{I} \kappa \mathrm{B} \alpha$. (B) Immunostaining of $\mathrm{p} 65$. Arrow indicates p65 translocation into the nucleus. PPB (200 $\mu \mathrm{g} / \mathrm{ml})$ inhibited LPS-induced p65 translocation into the nucleus. ${ }^{\# \# \# ~} \mathrm{P}<0.001$ vs. Veh; ${ }^{* * *} \mathrm{P}<0.001$ vs. Veh $+\mathrm{LPS}$. PPB, Prunus persica methanol extract; LPS, lipopolysaccharide; NF, nuclear factor; p-, phosphorylated; I, inhibitor; Veh, vehicle.

\section{Discussion}

The present study indicated that PPB presents anti-inflammatory effects on LPS-stimulated glial cells. PPB significantly decreased pro-inflammatory mediators and cytokines at the transcriptional level, which was accompanied by NF- $\mathrm{KB}$ and MAPK activation suppression in LPS-stimulated microglial cells. The present in vitro findings suggested PPB repressed NO production and p65 translocation in primary astrocytes.

Although iNOS is rarely expressed under normal conditions, it is highly expressed in activated glial cells under neuroinflammatory conditions (42). In contrast to other NOS enzymes in the brain, iNOS exerts neurotoxic effects through continuous NO production due to its calcium independence (43). Therefore, iNOS regulation is key to suppressing NO production in the presence of a neuroinflammatory stimulus. The inhibitory effect of PPB on NO release was examined via the suppression of iNOS expression. In addition, the expression levels of COX-2, which is the most representative proinflammatory mediator during an inflammatory response, was examined (44).

To clarify the protective role of PPB in glial cells, the LPS-induced neuroinflammation model was used. Peripheral LPS administration has not been effective in the brain because LPS could not penetrate the blood-brain barrier (BBB) (45). However, previous studies have indicated that LPS can induce neuroinflammation in the brain with minimal penetration (46) or BBB disruption (47). In previous studies, LPS treatment was considered a representative neuroinflammation model for several brain inflammatory cells, such as primary cultured astrocytes (48), microglia (49), BV2 cells (16) and C6 glioma cells (50). Therefore, the results of the present study suggested that PPB has suppressive effects in response to neuroinflammation.

Microglial cell activation increases the levels of certain neurotoxic and proinflammatory mediators and induces neuronal cell death, leading to various neuroinflammatory diseases $(9,16,17)$. Thus, the regulation of microglial cell activity alleviates neuroinflammation, which may further inhibit neuronal cell death. NF- $\mathrm{BB}$, a transcription factor, regulates the production of multiple genes related to immunity and inflammation (51). NF- $\mathrm{\kappa B}$ activation induces the transcription of proinflammatory genes through a variety of intracellular signaling pathways (52). In the cytoplasm, NF- $\mathrm{KB}$ is a heterotrimeric complex consisting of p50, p65, and ІкB subunits (39). Activation of this complex results in IкB phosphorylation and degradation, which leads to the translocation of NF- $\kappa B$ dimers (p50/p65 complex) to the nucleus as well as the activation of target genes, including proinflammatory 

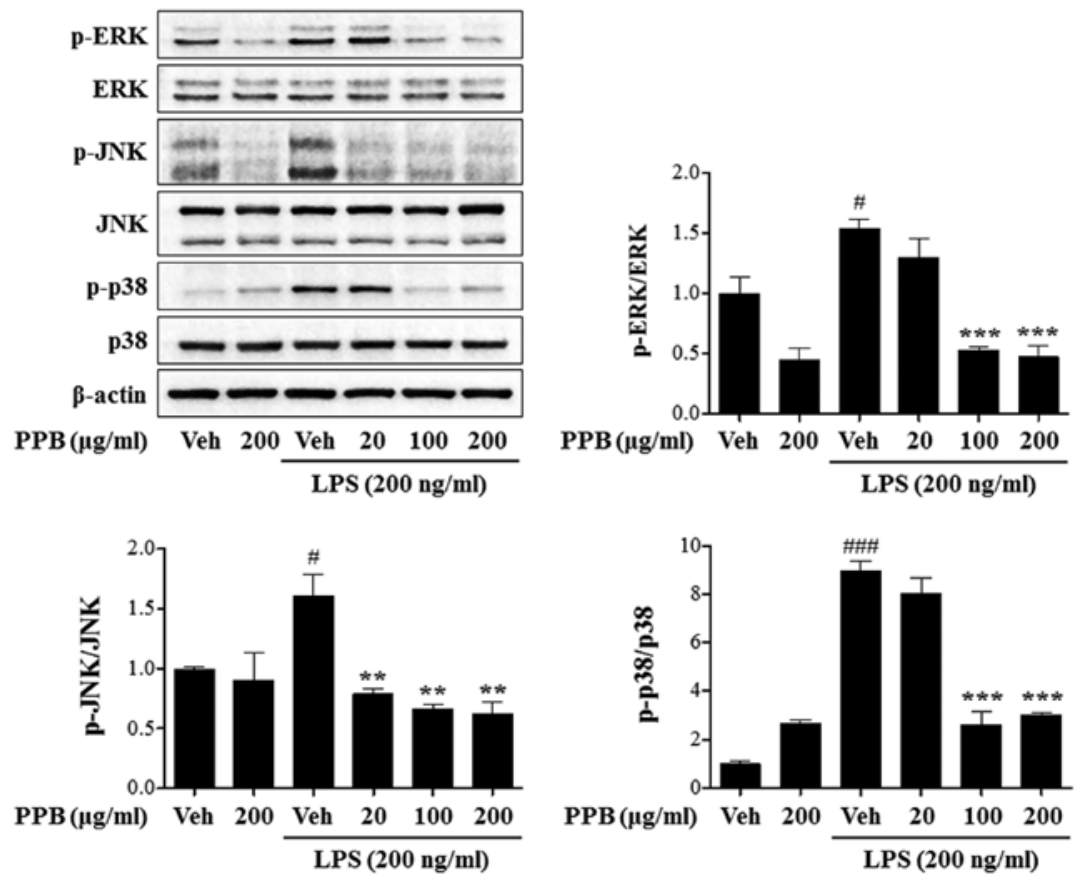

Figure 5. PPB inhibits MAPK activation in LPS-stimulated BV2 cells. Representative images of total and p-MAPK. p-MAPK is normalized with total MAPK. ${ }^{\#} \mathrm{P}<0.05,{ }^{\# \#} \mathrm{P}<0.001$ vs. Veh; ${ }^{* *} \mathrm{P}<0.01,{ }^{* * *} \mathrm{P}<0.001$ vs. Veh + LPS. PPB, Prunus persica methanol extract; LPS, lipopolysaccharide; p-, phosphorylated.
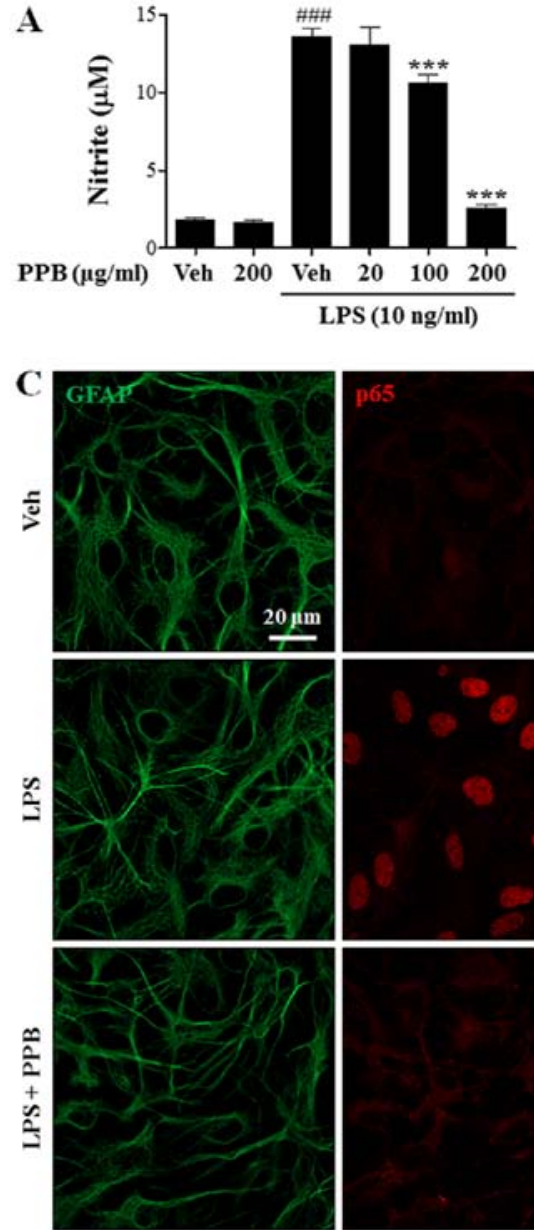
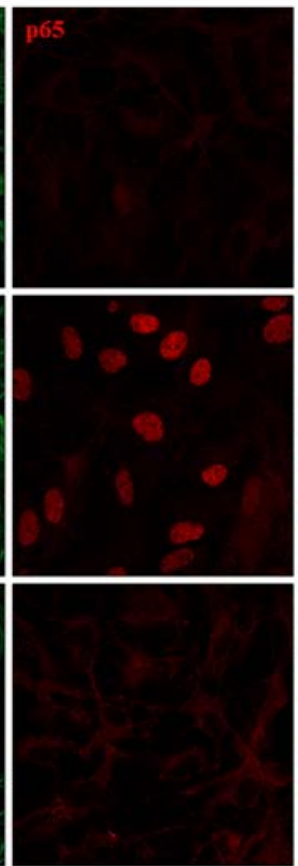

B
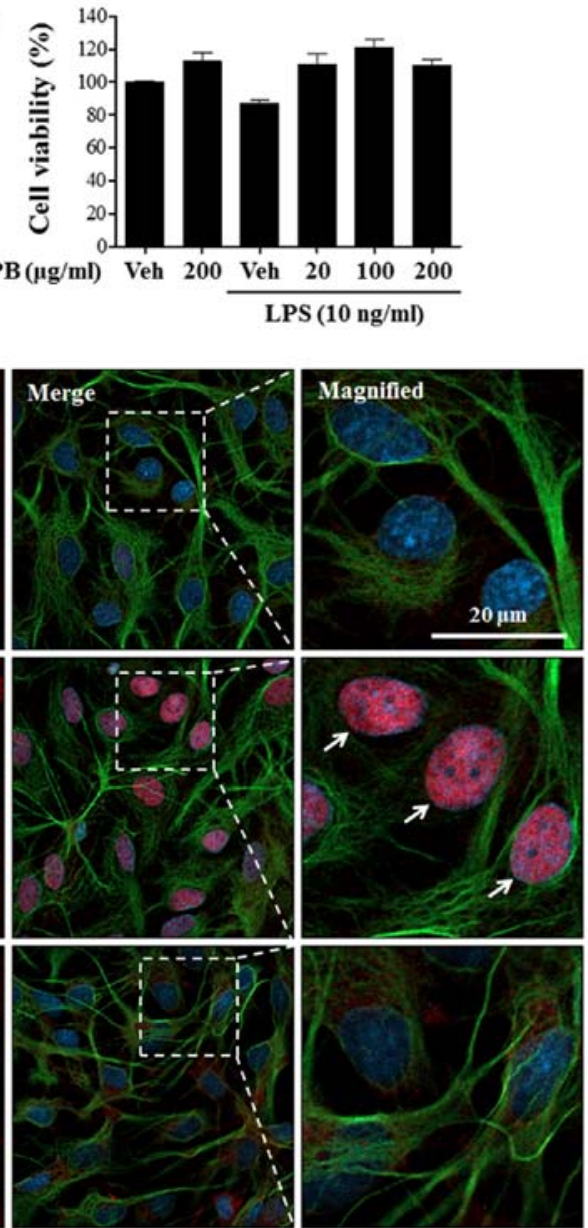

Figure 6. PPB inhibits nitrite production and 65 translocation in LPS-stimulated primary astrocytes. (A) Nitrite production in primary astrocytes. Astrocytes were treated with PPB and subsequently treated with LPS $(10 \mathrm{ng} / \mathrm{ml}) .{ }^{\# \# *} \mathrm{P}<0.001$ indicates a significant difference with the vehicle without LPS. ${ }^{* * *} \mathrm{P}<0.001$ indicates a significant difference in LPS treatment. (B) Cell viability measurement with the MTT assay. (C) Immunostaining of p65. Cultured astrocytes were stained with GFAP, and PPB $(200 \mu \mathrm{g} / \mathrm{ml})$ inhibited LPS-induced p65 translocation into the nucleus. Magnified images indicate p65 translocation into the nucleus (arrow). PPB, Prunus persica methanol extract; LPS, lipopolysaccharide; GFAP, glial fibrillary acidic protein; Veh, vehicle. 
cytokines (40). Thus, regulating NF- $\kappa B$ translocation is important in inflammatory diseases. The inhibitory activity of PPB may affect this signaling by acting as a suppressor of inflammatory mediators. Indeed, PPB inhibits IкB phosphorylation and p65 expression in the nucleus of LPS-stimulated BV2 cells and astrocytes. These findings suggest that the repression of inflammatory mediators by PPB is caused by NF- $\mathrm{\kappa B}$ signaling pathway inhibition.

MAPK signaling pathways (i.e., ERK, JNK and p38 MAPK) can regulate NF- $\kappa$ B activity in LPS-stimulated cells and participate in COX-2 and iNOS production (53). In in vivo and in vitro experiments, MAPK signaling pathways induce the activation of transcription factors and proinflammatory cytokines $(54,55)$. Activated ERK pathways induce COX-2 expression and PGE2 production in microglia (56). In primary astrocytes and microglia, LPS not only increases iNOS and TNF- $\alpha$ expression, but also induces MAPK activation (57). Consistent with these studies, the results of the present study showed that PPB inhibited MAPK activation in LPS-stimulated BV2 microglial cells, suggesting that its anti-inflammatory effects were also due to MAPK signaling pathway inhibition.

Epidemiological studies have suggested that phenolic compounds and carotenoid from peach pulps and peel decrease the risk of cardiac disorders, brain disorders and cancer because of their antioxidant and anti-inflammatory effect $(58,59)$. In addition, $P$. persica flower extract suppressed inflammation in LPS-simulated macrophages (60). It was hypothesized that the antioxidant effect of P.persica is derived from phenolics, flavonoids, and anthocyanins (58). Previous studies evaluating $P$. persica phenolic and flavonol content showed that chlorogenic acid and catechin were enriched in the peels and pulps of the fruit from P. persica cultivars (35). Likewise, PPB contained chlorogenic acid, catechin, quercetin, and quercetin-3-O-glucoside. This finding suggests that the anti-inflammatory effect of PPB in BV2 cells was due to the presence of phenolics and flavonols. In a previous study, chlorogenic acid suppressed glucose-induced glial cell activation (61). Moreover, neochlorogenic acid, an isomer of chlorogenic acid, inhibited the activation of LPS-induced microglia and p38 MAPK (62). Catechin also inhibited LPS-induced NO production in BV2 cells (63). In addition, the catechin flavonoid, epigallocatechin gallate, exerts a neuroprotective effect by suppressing glial cell activation induced by LPS (25) or $\beta$-amyloid (64). The present results indicated that the application of chlorogenic acid, catechin, or their combination may suppress the activation of glial cells. To further confirm whether the anti-inflammatory effect of PPB is due to the presence of chlorogenic acid or catechin, each bioactive molecule should be explored in future studies. In addition, future studies should also investigate whether PPB has a greater anti-inflammatory effect than chlorogenic acid or catechin alone due to the synergistic effect of bioactive molecules. Although results from BV2 cells or primary astrocytes may not reflect in vivo conditions, these findings suggest that PPB is a potential therapeutic agent for neuroinflammatory and neurodegenerative disease treatment via the repression of glial cell activation.

\section{Acknowledgements}

Not applicable.

\section{Funding}

The present study was supported by a National Research Foundation of Korea grant (no. 2017R1D1A1B03031920) funded by the Korean government and Chung-Ang University Research Scholarship Grants in 2018.

\section{Availability of data and materials}

The datasets used and/or analyzed during the present study are available from the corresponding author on reasonable request.

\section{Authors' contributions}

KHS performed the western blot analysis and maintained the cells. SYC designed the experiments and performed the immunocytochemistry analysis. YJ and YIK performed the RT-PCR. SE and TTB performed the nitrite and MTT assays. SHJ and HMY performed the western blot analysis for the translocation of NF- $\mathrm{kB}$. YSK supervised and performed $\mathrm{p} 65$ immunostaining experiments. WKW critically revised manuscript and designed astrocytes experiments for revision. SYJ performed PI staining and was involved in drafting the manuscript. HS performed the HPLC-MS/MS. WK supervised and resolved the PPB analysis. HMK designed and supervised the experiments. SHL designed overall experiments and drafted the manuscript.

\section{Ethics approval and consent to participate}

Not applicable.

\section{Patient consent for publication}

Not applicable.

\section{Competing interests}

The authors declare that they have no competing interests.

\section{References}

1. González-Scarano F and Baltuch G: Microglia as mediators of inflammatory and degenerative diseases. Annu Rev Neurosci 22: 219-240, 1999.

2. Maragakis NJ and Rothstein JD: Mechanisms of disease: Astrocytes in neurodegenerative disease. Nat Clin Pract Neurol 2: 679-689, 2006.

3. Prinz M and Priller J: Microglia and brain macrophages in the molecular age: From origin to neuropsychiatric disease. Nat Rev Neurosci 15: 300-312, 2014

4. Liu B and Hong JS: Role of microglia in inflammation-mediated neurodegenerative diseases: Mechanisms and strategies for therapeutic intervention. J Pharmacol Exp Ther 304: 1-7, 2003.

5. Sanchez Guajardo V, Tentillier N and Romero Ramos M: The relation between $\alpha$-synuclein and microglia in Parkinson's disease: Recent developments. Neuroscience 302: 47-58, 2015.

6. Keren Shaul H, Spinrad A, Weiner A, Matcovitch Natan O, Dvir Szternfeld R, Ulland TK, David E, Baruch K, Lara Astaiso D, Toth B, et al: A unique microglia type associated with restricting development of Alzheimer's disease. Cell 169: 1276-1290, 2017.

7. Kim DC, Lee DS, Ko W, Kim KW, Kim HJ, Yoon CS, Oh H and Kim YC: Heme oxygenase-1-inducing activity of 4-methoxydalbergione and 4'-hydroxy-4-methoxydalbergione from Dalbergia odorifera and their anti-inflammatory and cytoprotective effects in murine hippocampal and BV2 microglial cell line and primary rat microglial cells. Neurotox Res 33: 337-352, 2018. 
8. Liddelow SA, Guttenplan KA, Clarke LE, Bennett FC, Bohlen CJ, Schirmer L, Bennett ML, Münch AE, Chung WS, Peterson TC, et al: Neurotoxic reactive astrocytes are induced by activated microglia. Nature 541: 481-487, 2017

9. Dong Y and Benveniste EN: Immune function of astrocytes. Glia 36: 180-190, 2001

10. Wang X, Yang L, Yang L, Xing F, Yang H, Qin L, Lan Y, Wu H, Zhang B, Shi H, et al: Gypenoside IX suppresses p38 MAPK/Akt/NFKB signaling pathway activation and inflammatory responses in astrocytes stimulated by proinflammatory mediators. Inflammation 40: 2137-2150, 2017.

11. Zhang J, Benveniste H, Klitzman B and Piantadosi CA: Nitric oxide synthase inhibition and extracellular glutamate concentration after cerebral ischemia/reperfusion. Stroke 26: 298-304, 1995.

12. Law A, Gauthier S and Quirion R: Say NO to Alzheimer's disease: The putative links between nitric oxide and dementia of the Alzheimer's type. Brain Res Brain Res Rev 35: 73-96, 2001.

13. Block ML, Zecca L and Hong JS: Microglia-mediated neurotoxicity: Uncovering the molecular mechanisms. Nat Rev Neurosci 8: 57-69, 2007.

14. Jung WK, Lee DY, Park C, Choi YH, Choi I, Park SG, Seo SK, Lee SW, Yea SS, Ahn SC, et al: Cilostazol is anti-inflammatory in BV2 microglial cells by inactivating nuclear factor-kappaB and inhibiting mitogen-activated protein kinases. $\mathrm{Br}$ Pharmacol 159: 1274-1285, 2010.

15. Wilms H, Sievers J, Rickert U, Rostami-Yazdi M, Mrowietz U and Lucius R: Dimethylfumarate inhibits microglial and astrocytic inflammation by suppressing the synthesis of nitric oxide IL-1beta, TNF-alpha and IL- 6 in an in-vitro model of brain inflammation. J Neuroinflammation 7: 30, 2010.

16. Liu D, Wang Z, Liu S, Wang F, Zhao $S$ and Hao $A$ : Anti-inflammatory effects of fluoxetine in lipopolysaccharide (LPS)-stimulated microglial cells. Neuropharmacology 61 592-599, 2011

17. Boche D, Perry VH and Nicoll JA: Review: Activation patterns of microglia and their identification in the human brain. Neuropathol Appl Neurobiol 39: 3-18, 2013.

18. Recio MC, Andujar I and Rios JL: Anti-inflammatory agents from plants: Progress and potential. Curr Med Chem 19: 2088-2103, 2012.

19. Piotrowska H, Kucinska M and Murias M: Biological activity of piceatannol: Leaving the shadow of resveratrol. Mutat Res 750 60-82,2012.

20. Lee H, Kim YO, Kim H, Kim SY, Noh HS, Kang SS, Cho GJ, Choi WS and Suk K: Flavonoid wogonin from medicinal herb is neuroprotective by inhibiting inflammatory activation of microglia. FASEB J 17: 1943-1944, 2003.

21. Li FQ, Wang T, Pei Z, Liu B and Hong JS: Inhibition of microglial activation by the herbal flavonoid baicalein attenuates inflammation-mediated degeneration of dopaminergic neurons. J Neural Transm (Vienna) 112: 331-347, 2005.

22. Suk K, Lee H, Kang SS, Cho GJ and Choi WS: Flavonoid baicalein attenuates activation-induced cell death of brain microglia J Pharmacol Exp Ther 305: 638-645, 2003

23. Park JS, Park EM, Kim DH, Jung K, Jung JS, Lee EJ, Hyun JW, Kang JL and Kim HS: Anti-inflammatory mechanism of ginseng saponins in activated microglia. J Neuroimmunol 209: 40-49, 2009.

24. He LF, Chen HJ, Qian LH, Chen GY and Buzby JS: Curcumin protects pre-oligodendrocytes from activated microglia in vitro and in vivo. Brain Res 1339: 60-69, 2010.

25. Li R, Huang YG, Fang D and Le WD: (-)-Epigallocatechin gallate inhibits lipopolysaccharide-induced microglial activation and protects against inflammation-mediated dopaminergic neuronal injury. J Neurosci Res 78: 723-731, 2004

26. Choi DK, Koppula S and Suk K: Inhibitors of microglial neurotoxicity: Focus on natural products. Molecules 16: 1021-1043, 2011.

27. Shen $\mathrm{H}$, Wang $\mathrm{H}$, Wang L, Wang L, Zhu M, Ming Y, Zhao S, Fan J and Lai EY: Ethanol extract of root of Prunus persica inhibited the growth of liver cancer cell HepG2 by inducing cell cycle arrest and migration suppression. Evid Based Complement Alternat Med 2017: 8231936, 2017.

28. Rho JR, Jun CS, Ha Y, Yoo MJ, Cui MX, Baek HS, Lim JA, Lee YH and Chai KY: Isolation and characterization of a new alkaloid from the seed of Prunus persica L. and its anti-inflammatory activity. Bull Korean Chem Soc 28: 1289-1293, 2007.

29. Lee JY and An BJ: Anti-oxidant and anti-inflammation activities of prunus persica flos. J Appl Biol Chem 53: 162-169, 2010.
30. Kwak CS, Yang J, Shin CY and Chung JH: Topical or oral treatment of peach flower extract attenuates UV-induced epidermal thickening, matrix metalloproteinase-13 expression and pro-inflammatory cytokine production in hairless mice skin. Nutr Res Pract 12: 29-40, 2018.

31. Shin TY, Park SB, Yoo JS, Kim IK, Lee HS, Kwon TK, Kim MK, Kim JC and Kim SH: Anti-allergic inflammatory activity of the fruit of prunus persica: Role of calcium and NF-kappaB. Food Chem Toxicol 48: 2797-2802, 2010.

32. Benmehdi H, Fellah K, Amrouche A, Memmou F, Malainine H, Dalile $\mathrm{H}$ and Siata W: Phytochemical study, antioxidant activity and kinetic behaviour of flavonoids fractions isolated from prunus persica L. Leaves. Asian J Chem 29: 13, 2017.

33. Deb L, Gupta R, Dutta A, Yadav A, Bhowmik D and Kumar KS: Evaluation of antioxidant activity of aqueous fraction of Prunus persica L. aqueous extract. Der Pharmacia Sinica 1: 157-164, 2010.

34. Prakash V, Rana S and Sagar A: Studies on analysis of antibacterial and antioxidant activity of Prunus persica (L.) Batsch. Int J Sci Nat 8: 54-58, 2017.

35. Zhao X, Zhang W, Yin X, Su M, Sun C, Li X and Chen K Phenolic composition and antioxidant properties of different peach [Prunus persica (L.) Batsch] cultivars in China. Int J Mol Sci 16: 5762-5778, 2015

36. McCarthy KD and de Vellis J: Preparation of separate astroglial and oligodendroglial cell cultures from rat cerebral tissue. J Cell Biol 85: 890-902, 1980

37. NIH: Laboratory animal welfare. In: Special Edition of the NIH Guide for Grants and Contracts. NIH, Bethesda, MD, USA $85-23,1985$

38. Wrobel K, Claudio E, Segade F, Ramos S and Lazo PS Measurement of cytotoxicity by propidium iodide staining of target cell DNA: Application to the quantification of murine TNF-alpha. J Immunol Methods 189: 243-249, 1996.

39. Baldwin AS Jr: The NF-kappaB and I kappaB proteins: New discoveries and insights. Annu Rev Immunol 14: 649-683, 1996.

40. Mankan AK, Lawless MW, Gray SG, Kelleher D and McManus R: NF- kappaB regulation: The nuclear response. J Cell Mol Med 13: 631-643, 2009.

41. Oh YT,Lee JY,Lee J, Kim H, Yoon KS, Choe W and Kang I: Oleic acid reduces lipopolysaccharide-induced expression of iNOS and COX-2 in BV2 murine microglial cells: Possible involvement of reactive oxygen species, p38 MAPK, and IKK/NF-kappaB signaling pathways. Neurosci Lett 464: 93-97, 2009.

42. Mander P and Brown GC: Nitric oxide, hypoxia and brain inflammation. Biochem Soc Trans 32: 1068-1069, 2004

43. Pautz A, Art J, Hahn S, Nowag S, Voss C and Kleinert H: Regulation of the expression of inducible nitric oxide synthase. Nitric Oxide 23: 75-93, 2010

44. Bishop Bailey D, Calatayud S, Warner TD, Hla T and Mitchell JA: Prostaglandins and the regulation of tumor growth. J Environ Pathol Toxicol Oncol 21: 93-101, 2002.

45. Singh AK and Jiang Y: How does peripheral lipopolysaccharide induce gene expression in the brain of rats? Toxicology 201: 197-207, 2004

46. Banks WA and Robinson SM: Minimal penetration of lipopolysaccharide across the murine blood-brain barrier. Brain Behav Immun 24: 102-109, 2010

47. Banks WA, Gray AM, Erickson MA, Salameh TS Damodarasamy M, Sheibani N, Meabon JS, Wing EE, Morofuji Y, Cook DG and Reed MJ: Lipopolysaccharide-induced blood-brain barrier disruption: Roles of cyclooxygenase, oxidative stress, neuroinflammation, and elements of the neurovascular unit. J Neuroinflammation 12: 223, 2015.

48. Tarassishin L, Suh HS and Lee SC: LPS and IL-1 differentially activate mouse and human astrocytes: Role of CD14. Glia 62 999-1013, 2014.

49. Panicker N, Saminathan H, Jin H, Neal M, Harischandra DS, Gordon R, Kanthasamy K, Lawana V, Sarkar S, Luo J, et al: Fyn kinase regulates microglial neuroinflammatory responses in cell culture and animal models of Parkinson's disease. J Neurosci 35 10058-10077, 2015.

50. Kim YJ, Hwang SY and Han IO: Insoluble matrix components of glioma cells suppress LPS-mediated iNOS/NO induction in microglia. Biochem Biophys Res Commun 347: 731-738, 2006.

51. Bhatt D and Ghosh S: Regulation of the NF- $\kappa B-$ mediated transcription of inflammatory genes. Front Immunol 5: 71, 2014.

52. Lawrence T: The nuclear factor NF-kappaB pathway in inflammation. Cold Spring Harb Perspect Biol 1: a001651, 2009.

53. Lu YC, Yeh WC and Ohashi PS: LPS/TLR4 signal transduction pathway. Cytokine 42: 145-151, 2008. 
54. Korcheva V, Wong J, Corless C, Iordanov M and Magun B Administration of ricin induces a severe inflammatory response via nonredundant stimulation of ERK, JNK, and P38 MAPK and provides a mouse model of hemolytic uremic syndrome. Am J Pathol 166: 323-339, 2005.

55. Da Silva J, Pierrat B, Mary JL and Lesslauer W: Blockade of p38 mitogen-activated protein kinase pathway inhibits inducible nitric-oxide synthase expression in mouse astrocytes. J Biol Chem 272: 28373-28380, 1997.

56. Xia Q, Hu Q, Wang H, Yang H, Gao F, Ren H, Chen D, Fu C, Zheng L, Zhen X, et al: Induction of COX-2-PGE2 synthesis by activation of the MAPK/ERK pathway contributes to neuronal death triggered by TDP-43-depleted microglia. Cell Death Dis 6 : e1702, 2015.

57. Bhat NR, Zhang P, Lee JC and Hogan EL: Extracellular signal-regulated kinase and p38 subgroups of mitogen-activated protein kinases regulate inducible nitric oxide synthase and tumor necrosis factor- $\alpha$ gene expression in endotoxin-stimulated primary glial cultures. J Neurosci 18: 1633-1641, 1998.

58. Abidi W, Jiménez S, Moreno MÁ and Gogorcena Y: Evaluation of antioxidant compounds and total sugar content in a nectarine [Prunus persica (L.) Batsch] progeny. Int J Mol Sci 12: 6919-6935, 2011.

59. Gasparotto J, Somensi N, Bortolin RC, Moresco KS, Girardi CS, Klafke K, Rabelo TK, Morrone Mda S, Vizzotto M and Raseira Mdo C: Effects of different products of peach (Prunus persica L. Batsch) from a variety developed in southern Brazil on oxidative stress and inflammatory parameters in vitro and ex vivo. J Clin Biochem Nutr 55: 110-119, 2014.
60. Lee JY and An BJ: Antioxidant and anti-inflammatory effects of fractions from Pruni persicae Flos. Korea J Herbol 27: 55-63, 2012.

61. Mei X, Zhou L, Zhang T, Lu B, Sheng Y and Ji L: Chlorogenic acid attenuates diabetic retinopathy by reducing VEGF expression and inhibiting VEGF-mediated retinal neoangiogenesis. Vascul Pharmacol 101: 29-37, 2018.

62. Kim M, Choi SY, Lee P and Hur J: Neochlorogenic acid inhibits lipopolysaccharide-induced activation and pro-inflammatory responses in BV2 microglial cells. Neurochem Res 40: 1792-1798, 2015.

63. Li N, Wang Y, Li X, Zhang H, Zhou D, Wang W, Li W, Zhang X, Li X, Hou Y and Meng D: Bioactive phenols as potential neuroinflammation inhibitors from the leaves of Xanthoceras sorbifolia Bunge. Bioorg Med Chem Lett 26: 5018-5023, 2016.

64. Kim CY, Lee C, Park GH and Jang JH: Neuroprotective effect of epigallocatechin-3-gallate against $\beta$-amyloid-induced oxidative and nitrosative cell death via augmentation of antioxidant defense capacity. Arch Pharm Res 32: 869-881, 2009.

This work is licensed under a Creative Commons Attribution-NonCommercial-NoDerivatives 4.0 International (CC BY-NC-ND 4.0) License. 